\title{
Experiments and Modelling Techniques for Heat and Mass Transfer in Light Water Reactors
}

\author{
W. Ambrosini, M. Bucci, N. Forgione, A. Manfredini, and F. Oriolo \\ Dipartimento di Ingegneria Meccanica, Nucleare e della Produzione, Università di Pisa, Via Diotisalvi 2, 56126 Pisa, Italy \\ Correspondence should be addressed to W. Ambrosini, walter.ambrosini@ing.unipi.it
}

Received 29 October 2008; Accepted 22 December 2008

Recommended by Xu Cheng

\begin{abstract}
The paper summarizes the lesson learned from theoretical and experimental activities performed at the University of Pisa, Pisa, Italy, in past decades in order to develop a general methodology of analysis of heat and mass transfer phenomena of interest for nuclear reactor applications. An overview of previously published results is proposed, highlighting the rationale at the basis of the performed work and its relevant conclusions. Experimental data from different sources provided information for model development and assessment. They include condensation experiments performed at SIET (Piacenza, Italy) on the PANTHERS prototypical PCCS module, falling film evaporation tests for simulating AP600-like outer shell spraying conditions, performed at the University of Pisa, experimental data concerning condensation on finned tubes, collected by CISE (Piacenza, Italy) in the frame of the INCON EU Project, and experimental tests performed in the CONAN experimental facility installed at the University of Pisa. The experience gained in these activities is critically reviewed and discussed to highlight the relevant obtained conclusions and the perspectives for future work.
\end{abstract}

Copyright (c) 2009 W. Ambrosini et al. This is an open access article distributed under the Creative Commons Attribution License, which permits unrestricted use, distribution, and reproduction in any medium, provided the original work is properly cited.

\section{Introduction}

The capability to correctly model heat and mass transfer phenomena has a key role in the analysis of postulated accidents in present nuclear reactors and designs conceived for future deployment. In particular, steam condensation and water evaporation in the presence of noncondensable gases have been the subject of extensive studies in the past decades, mainly aiming to close the problem from the modelling point of view.

This effort was performed in many countries, particularly, in connection with the design of third generation reactors based on passive mechanisms for removing decay heat from the reactor vessel and the containment. Downscaled experimental facilities were set up reproducing basic heat and mass transfer phenomena occurring during normal and offnormal operations in such plants in order to collect relevant data (see e.g., [1-4]). In Europe, the objective of a more in depth understanding of these phenomena was attained also by projects financed in different EU framework programs, as those included in the INNO and CONT clusters of FP-4 [5] and in the FP-5 SCACEX Project [6].
The University of Pisa had an active part in these activities, contributing both by model development and assessment and by original experiments on both evaporation and condensation. The research started on the modelling side, with the analysis of available theories and techniques for evaluating condensation and evaporation rates in reactor systems [7]. In addition to empirical engineering correlations, the analogy between heat and mass transfer, in the different forms appearing in literature, was adopted as the basic tool for predicting mass transfer rates. Then, experimental data from different sources provided the relevant information for model development and assessment. In particular, the following:

(i) condensation experiments performed at SIET (Piacenza, Italy) on the PANTHERS-PCC prototypical passive containment cooling system modules were addressed by a $1 \mathrm{D}$ model [8];

(ii) falling film evaporation tests for simulating outer shell spraying conditions similar to those envisaged in AP600 reactor, were performed at the University of Pisa by the EFFE experimental facility and were 
simulated by both simplified models and a CFD code $[9,10]$;

(iii) condensation on finned tubes was then considered, adopting experimental data collected by tests performed at CISE (Italy) in the frame of the INCON EU Project [11];

(iv) experimental tests were carried out and are still running in the CONAN experimental facility installed at the University of Pisa [12] to study condensation in the presence of noncondensable gases, also in the frame of the EU Severe Accident Research Excellence Network (SARnet) of Excellence [13].

The experience gained in these different steps allowed refining modelling techniques ranging from simple engineering correlations to $1 \mathrm{D}$ and CFD models. In particular, the suitability of the analogy between heat and mass transfer was assessed in correlating both evaporation and condensation data $[9,10,12,14]$. The further step of applying CFD models in predicting heat and mass transfer was aimed to develop up-to-date modelling tools for light water reactor containment analysis $[13,15,16]$; this represents one of the most challenging aspects to be coped with in the years to come, in order to take full profit of the experimental information collected in the last decades, making a reasonable use of the increased capabilities of computational means.

The paper summarizes the relevant conclusions obtained in the above mentioned steps, trying to point out the lesson learned in relation to the available methodologies for evaluating heat and mass transfer in conditions of interest for nuclear reactor applications.

\section{Prediction of Condensation in a Prototypical PCCS Module}

In support to the design of components of the General Electric SBWR reactor [17], SIET set up a facility named PANTHERS-PCC in order to evaluate the effect of noncondensable gas build-up in the tubes of the SBWR passive containment cooling system condenser $[18,19]$.

The PCC test loop consisted of a pool tank housing the full-scale prototype, made of two equal modules submerged in water (see Figure 1). The number of vertical tubes in each module was 248, having $5.08 \mathrm{~cm}$ (2 inches) outer diameter and being connected with upper and lower headers. The air-steam mixture was introduced in the condenser at prescribed values of air and steam flow rates, pressures, and temperatures. The steam condensed partly on the inner walls of the tubes and was collected in the lower header and routed to a drain tank; the latter represents the gravity driven coolant system pool of the full scale reactor. Coherently with the mechanisms envisaged to occur in the SBWR reactor, air accumulating in the gas space of the drain tank was discharged to a vent tank, maintained at a slightly lower pressure than the PCC inlet and outlet, thus, simulating the behavior of the pressure suppression pool in the SBWR. The experimental facility preserved the elevation of the full-scale

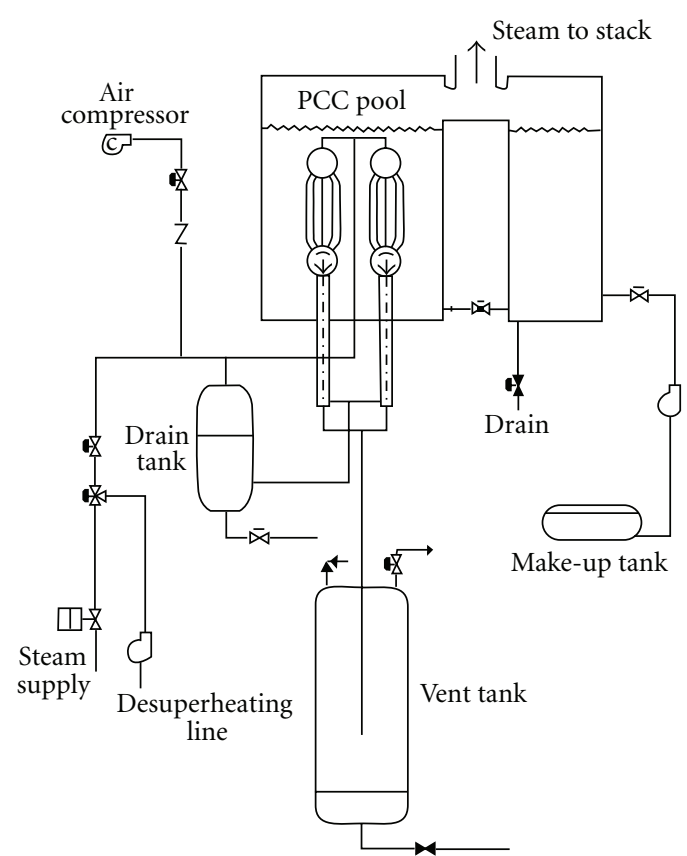

Figure 1: PANTHERS-PCC test facility.

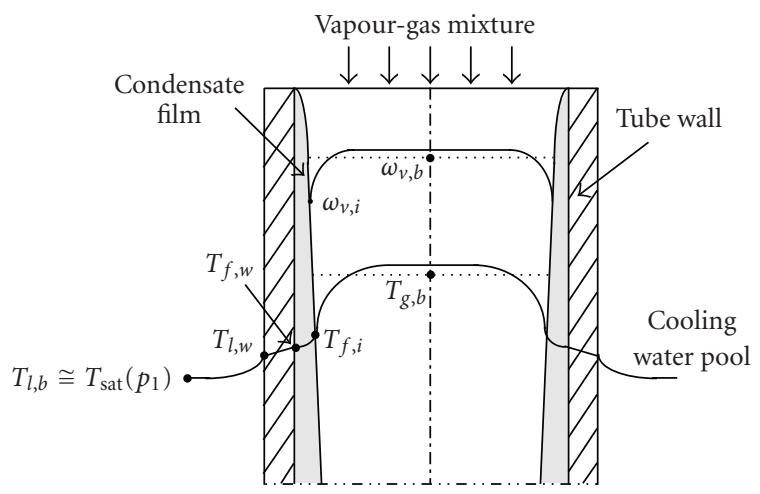

Figure 2: Physical model adopted for film condensation in tubes.

plant, in order to correctly simulate the expected gravity driven phenomena.

Different series of tests were performed in the facility aiming at simulating the main characteristics of the SBWR design basis accidents. The tests involved different degrees of superheating of the air-steam mixture and different air mass fractions; the effect of level in the water pool was also tested.

The 1D model adopted by the University of Pisa in this frame [8] was developed in order to simulate both filmwise condensation and falling film evaporation. A schematic representation of the geometrical and operating conditions assumed in the model in the case of film condensation in tubes is reported in Figure 2. The model makes use of a complete nonequilibrium two-fluid approach, solving separate steady-state mass, energy, and momentum balance equations for each phase, discretized by a finite difference scheme. Several tens of control volumes were adopted to axially discretize the PCC tubes. 
The Rohsenow boiling heat transfer correlation [20] was adopted on the outer side of the heat exchanger tubes, as in many tests the outer fluid temperature was very close to saturation and boiling conditions could be envisaged. The modelling of the gas-liquid interfacial heat and mass transfer, having the greatest importance in order to evaluate the overall efficiency of the heat exchanger, relied on the analogy between heat and mass transfer, adopting different heat transfer correlations. In particular, in a base model, the classical Dittus and Boelter correlation [21] was adopted in the forms

$$
\begin{aligned}
& \mathrm{Nu}_{g, i, \infty}=0.023 \operatorname{Re}_{g, i}^{0.8} \operatorname{Pr}_{g}^{0.3}, \\
& \mathrm{Sh}_{g, 0, \infty}=0.023 \operatorname{Re}_{g, i}^{0.8} \mathrm{Sc}_{g}^{0.3} .
\end{aligned}
$$

The asymptotic values of the heat transfer coefficients, applicable in long tubes, were then corrected taking into account entrance effects according to a correlation suggested by Bonilla [22]. Once the corrected Sherwood number at low mass transfer rate, $\mathrm{Sh}_{g, 0}$, was calculated, the condensation heat transfer was evaluated by the following relationship:

$$
\begin{gathered}
q_{\text {cond }}^{\prime \prime}=h_{l v} \frac{\mathrm{Sh}_{g, 0} \mathrm{D}_{v g} \rho_{g}}{D_{h}} \ln \left(1+B_{m}\right) \\
B_{m}=\frac{\omega_{v, i}-\omega_{v, b}}{1-\omega_{v, i}}
\end{gathered}
$$

taking into account the suction effect by the classical formulation derived from the solution of the Stefan's problem [23]. Similarly, the Ackerman correction for the heat transfer coefficient [24] was adopted.

As found in previous experiences of code applications by other researchers (see the discussion in [8]), two variants of the model were introduced, adopting a correlation by Banerjee and Hassan [25] and taking into account evidence from experiments pointed out by Almenas and Lee [26], concerning the dependence of heat transfer coefficients on system pressure. In particular, as in the Banerjee and Hassan [25] model, a minimum value of the Nusselt number was imposed adopting the formulations:

$$
\begin{gathered}
\mathrm{Nu}_{g, i, \mathrm{tu}}=0.023 \operatorname{Re}_{g, i}^{0.8} \operatorname{Pr}_{g}^{0.3}, \\
\mathrm{Nu}_{g, i, \text { min }}=5.5\left(\frac{p}{p_{0}}\right)^{1.2}, \\
\mathrm{Nu}_{g, i}=\left[\left(\mathrm{Nu}_{g, i, \mathrm{tu}}\right)^{3}+\left(\mathrm{Nu}_{g, i, \mathrm{~min}}\right)^{3}\right]^{1 / 3},
\end{gathered}
$$

with $p_{0}=0.1 \mathrm{MPa}$.

The obtained results showed an increasingly better behavior in predicting the trend of condenser efficiency by applying the basic model, the Banerjee and Hassan [25] model and the final proposed model, which implemented the suggestion by Almenas and Lee [26] expressed in (3). The overall performance of the model in predicting condensation efficiency, also as a function of pressure, is described in Figure 3, showing that the final proposed model was able to predict with good accuracy the observed experimental data.

\section{Falling Film Evaporation}

The EFFE experimental facility [27] was set up in order to provide separate effect data on falling film evaporation in conditions similar to those envisaged for the outer surface of the AP600 safety envelope after a postulated loss of coolant accident. The facility consisted in a $0.6 \mathrm{~m}$ wide, twometer-long stainless steel plate, heated on the back side by 100 modular electric heaters. The heaters were arranged in three groups, supplied by the three phases of an electrical transformer, in order to separately control heat flux in the film inlet, middle, and outlet sections $[9,10]$.

The plate was mounted over a frame allowing to rotate it from the completely vertical to the completely horizontal position (Figure 4(a)), in order to allow for simulating the conditions occurring along the vertical part of the AP600 containment shell and in the upper dome. A water spray system, located at the top of the plate (labelled Distr in Figure $4(\mathrm{~b})$ ), allowed for distributing in a uniform fashion the falling film on the heated surface; a transparent screen $(P p)$, located approximately at a distance of $10 \mathrm{~cm}$ from the heated surface, contributed to enclose the evaporating region into a square channel. A countercurrent air flow was forced in the channel by a blower $(B l)$ located at the bottom of the plate itself, thus, reproducing conditions similar to those occurring in the external AP600 containment flow paths owing to natural draft. The overall evaporation rate was measured in different ways, in order to allow for cross-checking the measured values; the most accurate measurement was achieved by the rate of decrease of water level in the reservoir $(M v)$, obtained by continuously acquiring a differential pressure signal between the bottom of the vessel and the external atmosphere.

The experimental facility was operated in the frame of the EU DABASCO Project [5], devoted to acquire experimental data on containment phenomena. Both dry (i.e., pure forced convection) and wet (i.e., film evaporation) tests were performed, aiming to compare the average Nusselt number data obtained in the former with corresponding averaged Sherwood numbers obtained in the latter. Film flow rates from 20 to $100 \mathrm{~g} / \mathrm{s}$ were adopted, together with velocities of the countercurrent air flow up to nearly $9 \mathrm{~m} / \mathrm{s}$ and plate temperatures from 50 to $90^{\circ} \mathrm{C}$.

The obtained heat and mass transfer experimental data showed a general coherence with the analogy between heat and mass transfer, as shown in Figure 5, reporting average values of the Nusselt and the Sherwood numbers for corresponding tests at 50 and $60^{\circ} \mathrm{C}$ of nominal plate temperature. As it can be noted, the heat transfer correlation obtained from dry tests approaches the classical correlation for heat transfer in closed ducts multiplied by a coefficient larger than unity, accounting for the limited length of the pipe and for the effect of the thrust generated by the blower located at channel inlet; on the other hand, wet test data, in terms of Sherwood number exhibit a similar behavior, supporting the applicability of the analogy between heat and mass transfer. This conclusion was confirmed by data at higher plate temperatures (from 70 to $90^{\circ} \mathrm{C}$ ) [10]. 


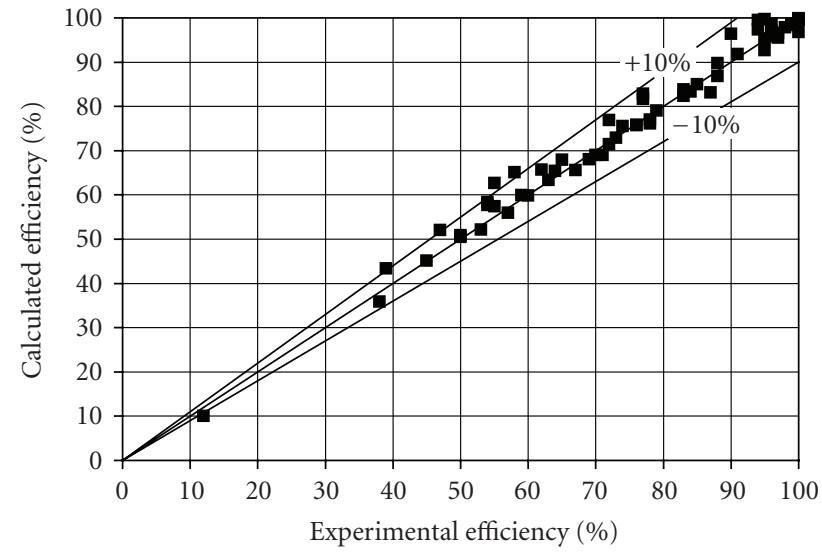

(a)

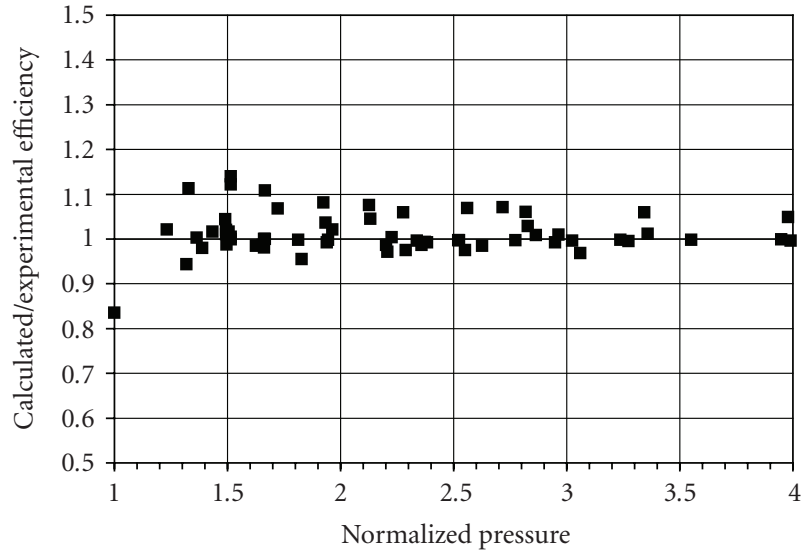

(b)

FIGURE 3: Performance of the adopted model in predicting condensation efficiency as observed in PANTHERS-PCC tests.

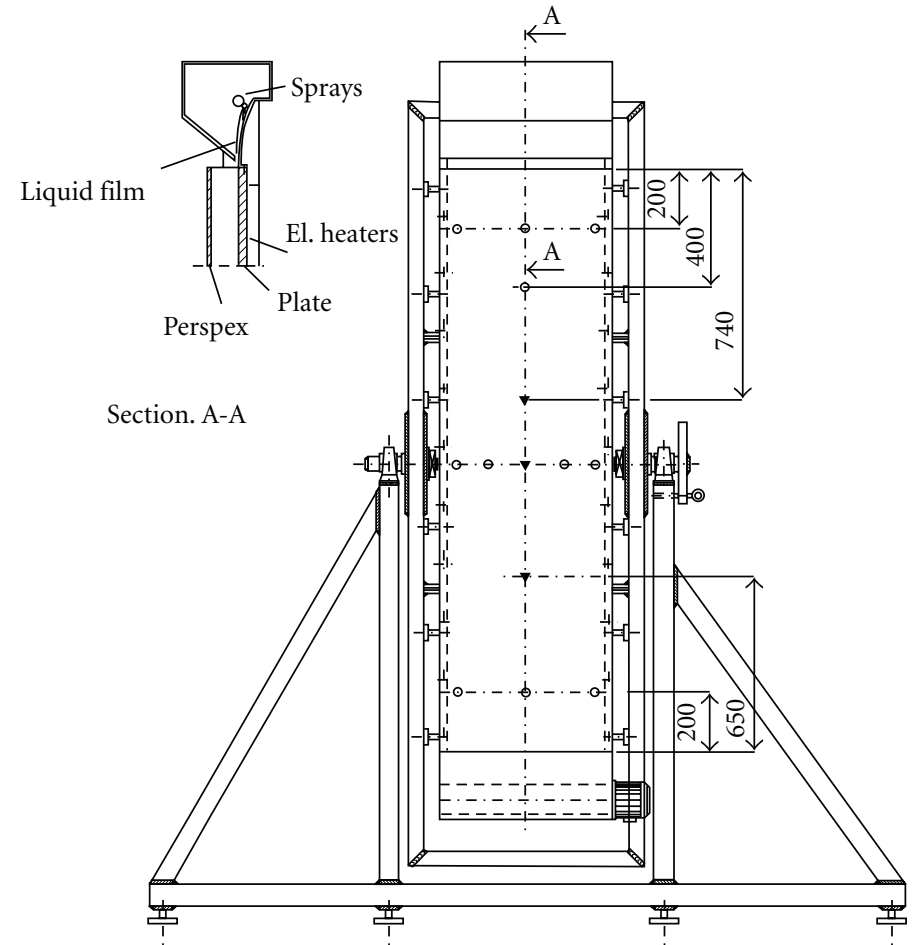

- Single thermocouple at plate surface

v Number 3 thermocouples at different height in the plate thickness

(a) Front view of the plate

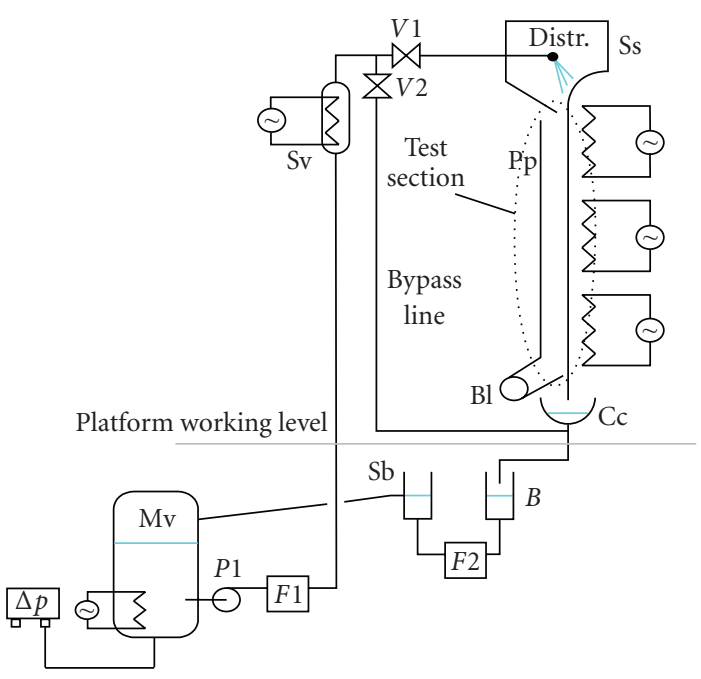

(b) Flow diagram

FIgURE 4: EFFE Experimental Facility.

The availability of experimental data on falling film evaporation offered a first opportunity to apply computational fluid dynamics in simulating heat and mass transfer in a flow duct [15]. The adopted model, quite similar to the ones to be used later on for filmwise condensation, exploited the opportunities offered by the FLUENT code [28] to simulate the near-wall region with models having different degrees of low-Reynolds number capabilities. In particular, the RNG $k-\varepsilon$ model was adopted with the twolayer standard model available in the CFD code, making use of detailed discretizations close to the walls. In particular, a $2 \mathrm{D} 46 \times 46,90 \times 90$ or $180 \times 180$ grid was chosen with a refined distribution of meshes close to the lateral walls and at the channel inlet. The falling film was not 


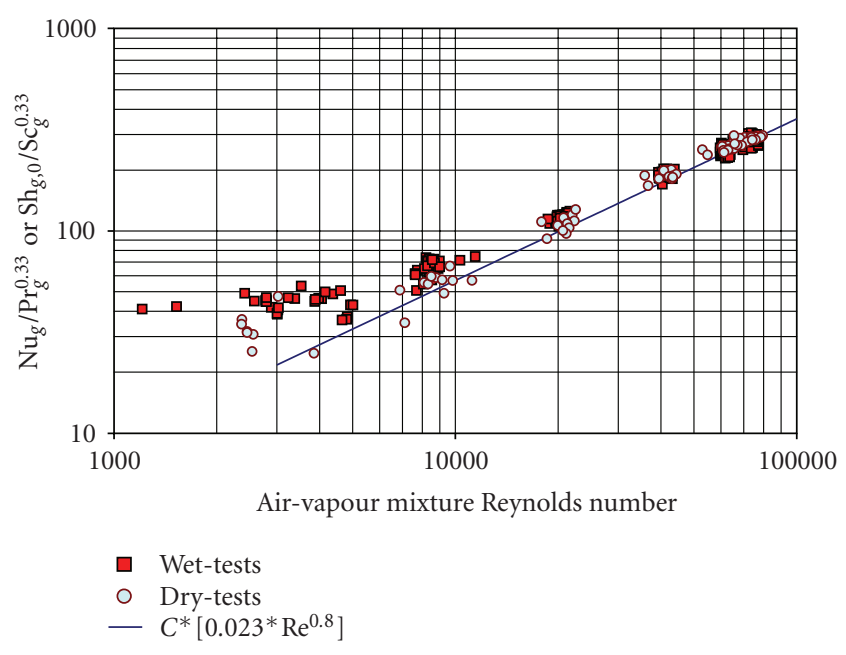

FIGURE 5: Comparison of dry and wet test data in the experimental test series at $50^{\circ} \mathrm{C}$ and $60^{\circ} \mathrm{C}$ of plate temperature in the EFFE experiments [6].

modelled, due to its minor role in determining heat and mass transfer; the evaporating wall was therefore assumed as a still interface at the measured average temperature. Water vapour concentration at the wall was assumed to be at the value corresponding to saturation at the wall temperature.

Since the evaporating wall could not be assumed permeable to vapour, as it should be for a transpiration problem in which vapour is continuously blown from the film into the gas-steam mixture, equivalent mass and energy sources were assumed to exist in the first mesh layer close to the wall, having a thickness $\Delta$ in the order of $10^{-4} \mathrm{~m}$. This approach, subsequently used also for simulating film condensation, makes use of the available user defined functions to assume volumetric sources given by

$$
S_{m}=\dot{m}_{i}^{\prime \prime} / \Delta=-\left.\frac{\rho_{g, i} \mathrm{D}_{v g}}{1-\omega_{v, i}} \frac{\partial \omega_{v}}{\partial y}\right|_{i} / \Delta
$$

for mass, and

$$
S_{h}=S_{m} h_{v}
$$

for energy.

The results obtained for the dry and wet experimental tests, whose boundary conditions are reported in Table 1, showed a tendency to underestimate heat transfer and evaporation rates (see Table 2 for the case $V_{\text {in }}=0$ ). This effect could be attributed to the location of the blower close to the channel inlet, possibly impressing a transversal component to the inlet velocity. As a matter of fact, the calculations performed with a $45^{\circ} \mathrm{C}$ degree inclination of the inlet flow rate (see Table 2 for the case $V_{\text {in }}=U_{\text {in }}$ ) showed powers and evaporation rates more coherent or even in excess with the measured values confirming the possibility that such an effect plays a role in the performed experiments.

\section{Condensation on Finned Tubes}

The proposal made in the early 90s by ENEL, Italy, the Italian electrical utility, of a double containment equipped with a completely passive heat removal system [29], stimulated a renewed interest for condensation on finned heat exchangers. In fact, the proposed design included a number of compact heat exchangers made of arrays of inclined finned tubes, connected through a natural circulation loop to an external heat exchanger.

As the efficiency of this system had to be clearly proven in front of safety requirements, an experimental campaign was then carried out by ENEL in cooperation with different Europe an partners. The activity involved an extensive testing of major components, including the internal heat exchanger, the intermediate loop, and the external pools. In particular, CISE performed an extensive campaign on both smooth and finned single tubes in natural convection conditions [30]; in addition, both CISE and PSI [31] performed functional tests on compact finned tube heat exchangers, making use of different modalities. Figure 7 shows sketches of the experimental apparatuses adopted by CISE in this purpose.

This new experimental information allowed the University of Pisa to set up models for finned tube condensation, testing different heat transfer correlation and applying the heat and mass transfer analogy. The main characteristics of the models were the following.

(i) Based on available correlations for heat transfer in free or forced convection on finned tubes and compact heat exchangers, the analogy between heat and mass transfer was applied in the form

$$
\begin{aligned}
\mathrm{Nu} & =f(\mathrm{Re}, \mathrm{Gr}, \operatorname{Pr}, \text { geometry }) \\
& \Longrightarrow \mathrm{Sh}_{0}=f(\operatorname{Re}, \mathrm{Gr}, \mathrm{Sc}, \text { geometry })
\end{aligned}
$$

where $f$ represents the particular heat transfer correlation identified for the application and $\mathrm{Sh}_{0}$ represents the Sherwood number at low mass transfer rate, to be corrected by the classical logarithmic relationship derived by the solution of the Stefan problem:

$$
\mathrm{Sh}=\frac{h_{m} D}{\rho_{g} \mathrm{D}_{v g}}=\operatorname{Sh}_{0} \frac{\ln \left(1+B_{m}\right)}{B_{m}},
$$

the corresponding mass transfer rate was calculated as

$$
\dot{m}_{i}^{\prime \prime}=h_{m} B_{m}=h_{m} \frac{\omega_{v, i}-\omega_{v, b}}{1-\omega_{v, i}} .
$$

(ii) Since in the case of condensation, the presence of a finned surface raises the problem of evaluating the overall surface efficiency and also the effect of "bridging" (or flooding) of the fins with liquid condensate, it was necessary to include models for both these effects; in particular, the Beatty and Katz model [32] was used to combine the heat transfer coefficients of the finned and unfinned surfaces 


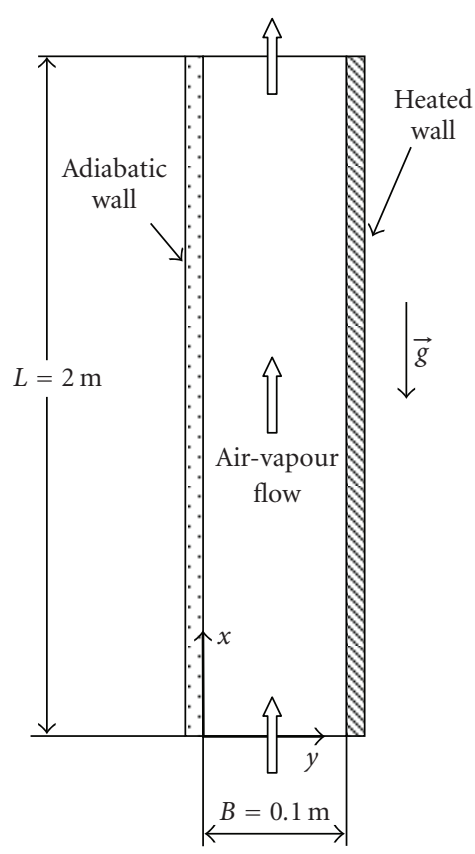

(a) Computational domain

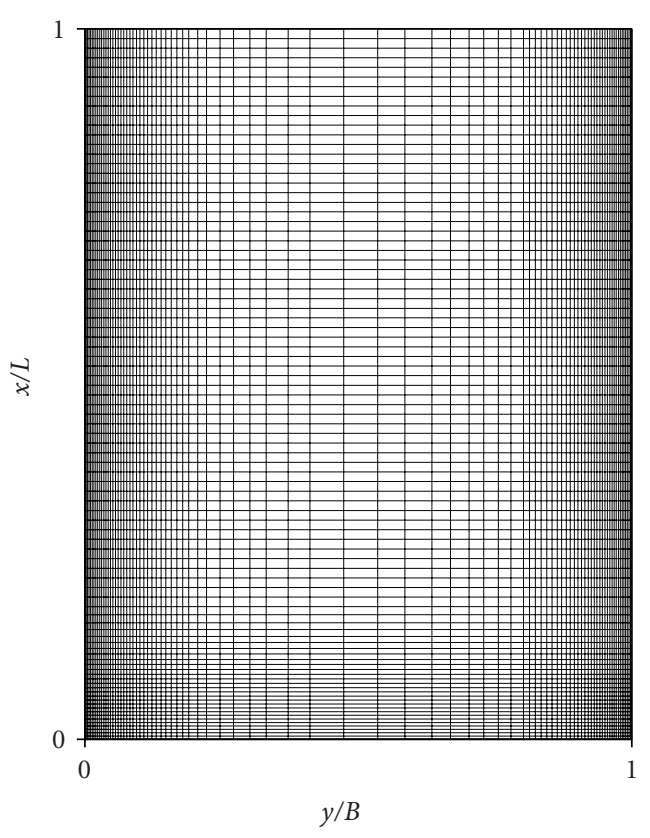

(b) Discretization

FIgURE 6: Computational domain and discretization of the channel of the EFFE experimental facility for the FLUENT code.

TABLE 1: Boundary conditions for the dry and wet EFFE tests addressed by FLUENT calculations [15].

\begin{tabular}{|c|c|c|c|c|c|}
\hline & \multirow[b]{2}{*}{ Test no. } & \multirow[b]{2}{*}{$\begin{array}{c}\text { Average plate } \\
\text { temperature }\left({ }^{\circ} \mathrm{C}\right)\end{array}$} & \multicolumn{3}{|c|}{ Air flow } \\
\hline & & & $\begin{array}{l}\text { Inlet temperature } \\
\left({ }^{\circ} \mathrm{C}\right)\end{array}$ & $\begin{array}{l}\text { Relative humidity } \\
(\%)\end{array}$ & $\begin{array}{l}\text { Mean inlet velocity } \\
(\mathrm{m} / \mathrm{s})\end{array}$ \\
\hline \multirow{3}{*}{ Dry } & DTI & 57.8 & 20.8 & 47.6 & 0.87 \\
\hline & DT2 & 56.9 & 21.2 & 47.5 & 4.25 \\
\hline & DT3 & 57.5 & 24.0 & 43.3 & 7.47 \\
\hline \multirow{3}{*}{ Wet } & WTI & 60.3 & 23.5 & 30.9 & 0.78 \\
\hline & WT2 & 60.8 & 23.6 & 34.6 & 4.07 \\
\hline & WT3 & 60.5 & 25.0 & 38.2 & 7.24 \\
\hline
\end{tabular}

based on the film condensation Nusselt theory for flat plates; in addition, the Rudy and Webb model [33] was initially adopted for evaluating the possible effect of efficiency reduction due to bridging, but it was later recognized that this phenomenon played a minor role in the experiments and it was finally neglected; in the final form of the model, also the thermal resistance of the liquid film at the condensing surface was neglected, since it was found to introduce a very weak effect.

Figures 8 and 9 show the results obtained for both the case of single-finned tubes in natural convection and for compact-finned tube heat exchangers with natural draft (CISE) and forced convection (PSI). As it can be noted, also for this relatively more complicated case, the application of the analogy between heat and mass transfer showed to be successful enough as to provide a good comparison with the reference base of data.

\section{Filmwise Condensation onto a Flat Plate}

Recently, the University of Pisa undertook experiments on filmwise condensation in the CONAN experimental facility installed at its laboratories [12, 13, 16, 35]. As shown in Figure 10, the experimental facility includes three loops.

(i) The primary loop, containing a square cross-section $(0.34 \mathrm{~m} \times 0.34 \mathrm{~m})$, two-meter-long test channel, facing a $4.5 \mathrm{~cm}$ thick aluminium plate $(0.34 \mathrm{~m} \times 2 \mathrm{~m}$, in width and length) on which condensation takes place; the loop presently operates at atmospheric pressure and the steam content in the air-steam mixture circulated in the facility is controlled by the electrical power fed to the steam generator (capable of $60 \mathrm{~kW}$ ).

(ii) The secondary loop provides the needed cooling on the back side of the cooling plate, by circulating relatively cold water in a narrow channel $(5 \mathrm{~mm}$ of depth); the measurements of the secondary coolant 
TABLE 2: Results obtained by the FLUENT calculations for the dry and wet EFFE tests [15].

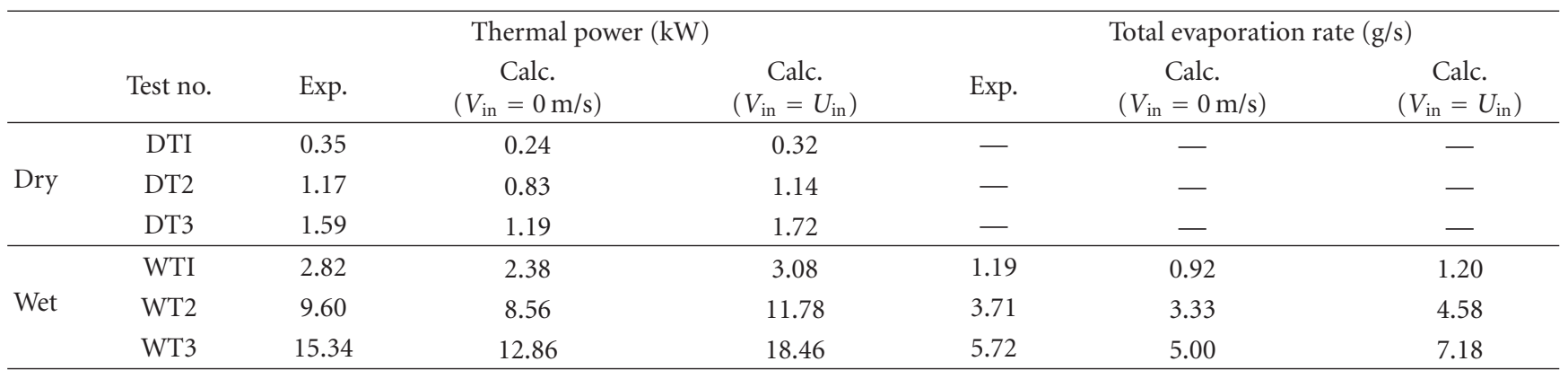

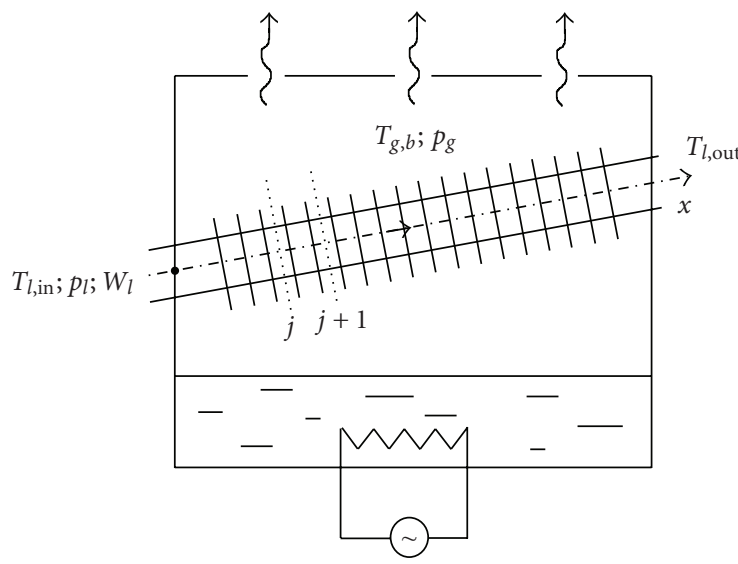

(a)

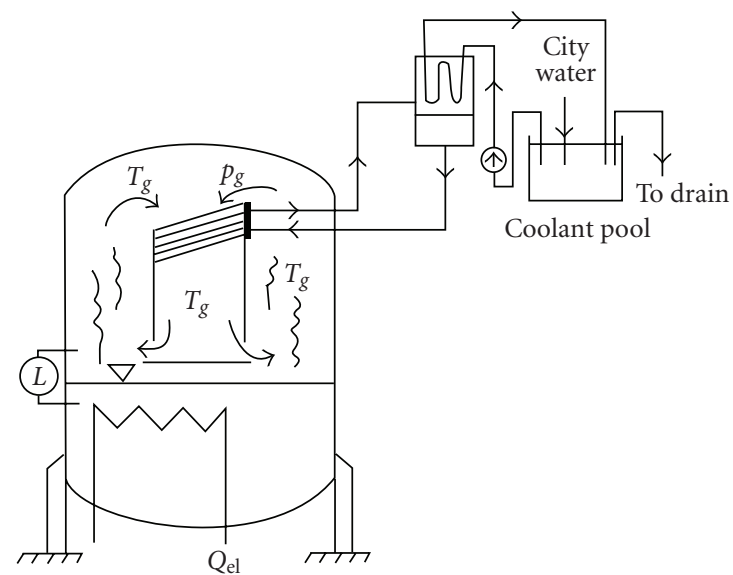

(b)

FIGURE 7: Sketches of the experimental apparatuses adopted by CISE for single tubes and full compact heat exchanger mock-ups [11].

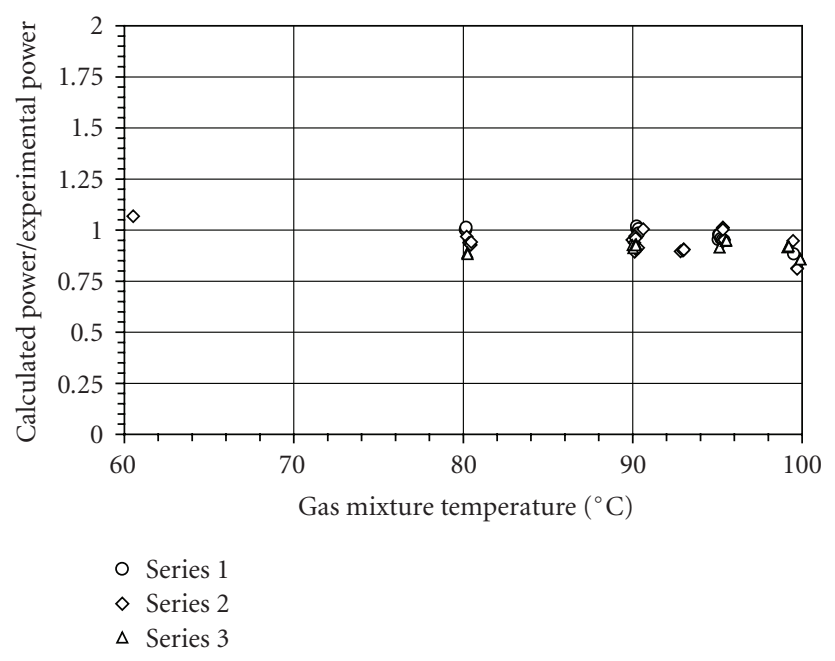

Figure 8: Results obtained for natural convection condensation on single-finned tubes by the Tsubouchi and Masuda model [34].

conditions on the back side of the plate represent important information to be provided for modelling, relying on the measured inlet and outlet secondary coolant temperature and flow rate to evaluate the heat transfer coefficient and the average secondary fluid temperature.

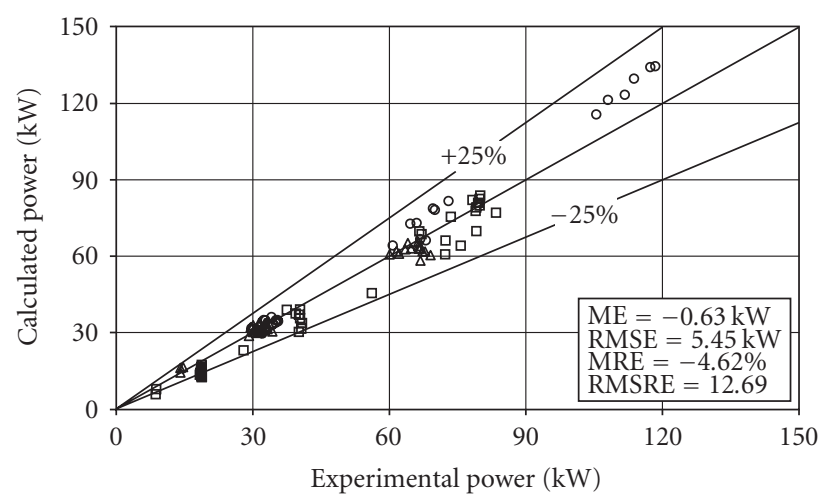

口 CISE inner HX functional tests

$\Delta$ PSI inner HX char. tests (1st mock-up)

- PSI inner HX char. tests (2nd mock-up)

Figure 9: Results obtained for condensation on compact-finned tube heat exchangers making use of the Nir model [34].

(iii) The tertiary loop, interfaced with the secondary one through a mixing vessel, accomplishes with the function to remove heat from the test section, by extracting a prescribed flow of warm water from the vessel and replacing it with a same flow of colder water from a large reservoir. 


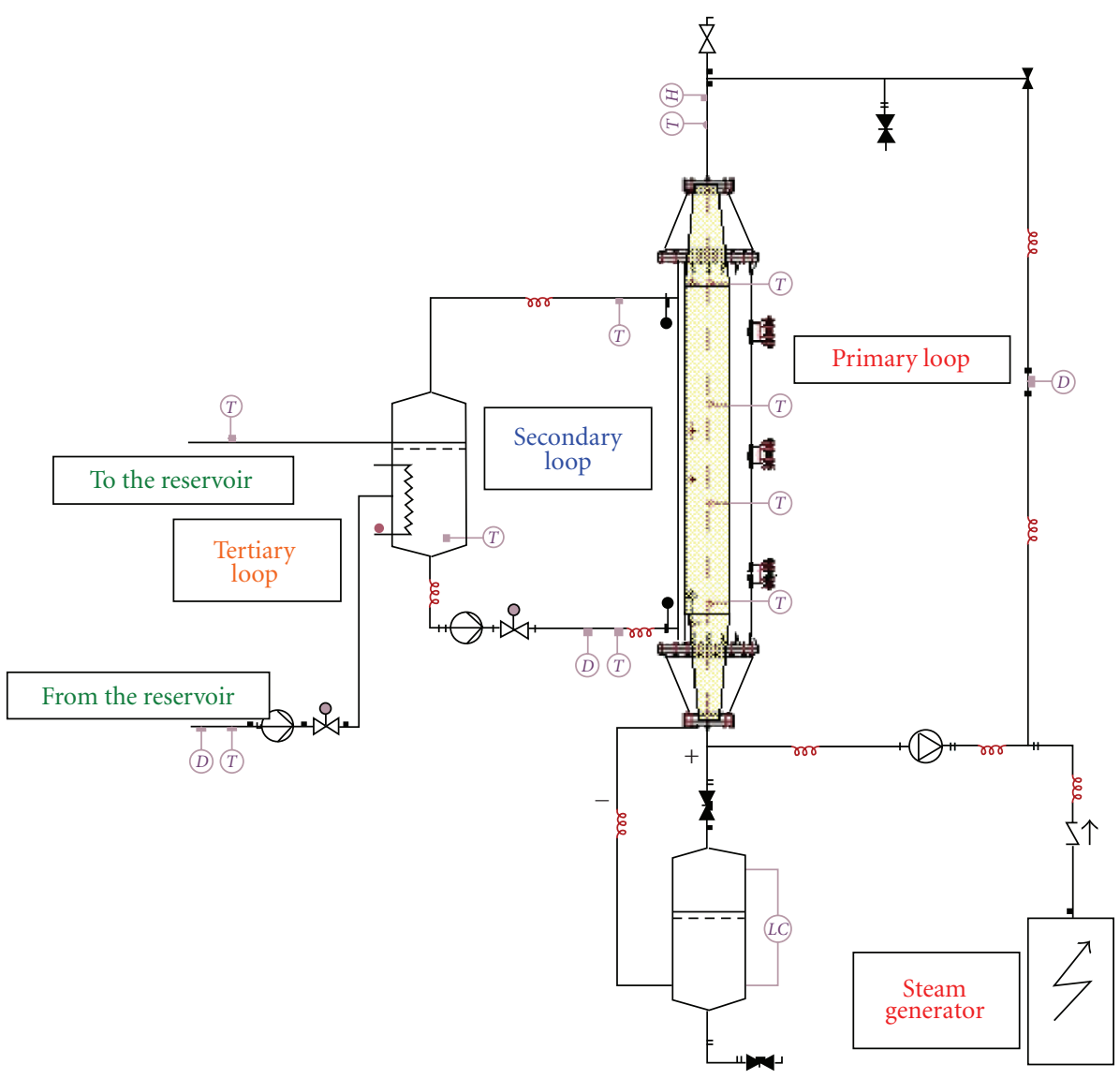

FIgURE 10: Flow diagram of the CONAN experimental facility.

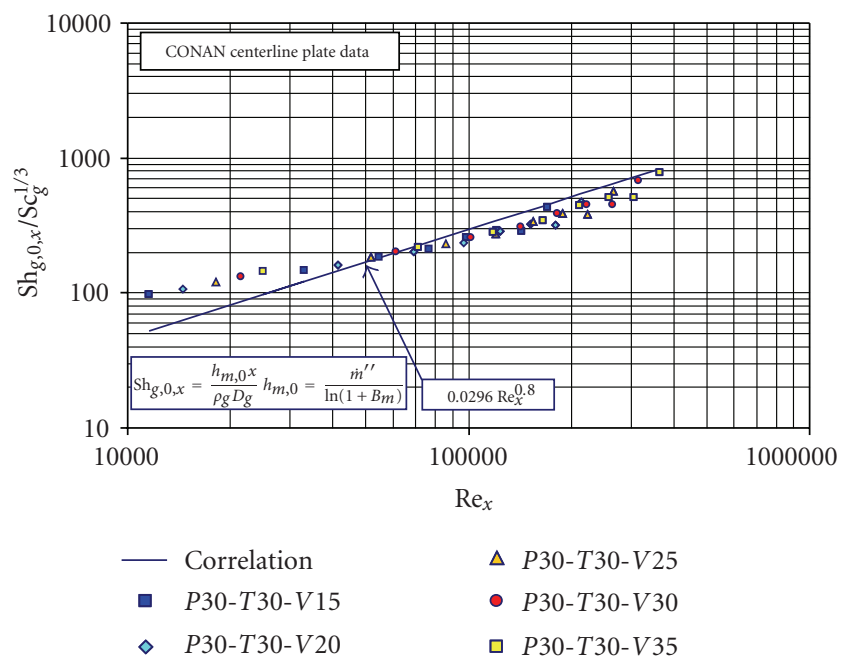

FIGURE 11: Comparison of a set of experimental data from the CONAN facility with an engineering correlation [16].

The relevant measurements available in the facility include the primary air-steam mixture flow rate (corresponding to channel velocities in the range from 1.5 to $3.5 \mathrm{~m} / \mathrm{s}$ ), dry-bulb and wet-bulb tempe ratures, the local tempe rature close to the surface and within the thickness of the cooled plate (from
30 to $70^{\circ} \mathrm{C}$ ) and the overall condensate flow rate, as collected by a gutter.

In addition to comparing the results of the measurements in terms of local Sherwood numbers with available engineering correlations (see Figure 11), the experimental data were compared with the predictions obtained by the FLUENT code in which a $2 \mathrm{D}$ model very similar to the one adopted in the case of the evaporation tests described above (see Section 3) was used. In making use of the model, a conjugated heat transfer approach was successfully implemented, by discretizing the cooled plate and simulating heat conduction through it, in addition to condensation on the gas-side surface (Figure 12). Also in this case, the RNG $k-\varepsilon$ model was used with a two-layer treatment near the wall. Appropriate sinks of mass and energy are introduced near the wall to simulate the steam suction. The overall good agreement obtained in the general comparison with data (Figure 13) encouraged to improve the measurement techniques and to analyze in greater detail the phenomena and the observed slight discrepancies with experimental data.

In particular, specific tests performed in the CONAN facility were proposed as Step 1 of a condensation benchmark organized by the University of Pisa in the frame of the EU SARnet of Excellence [13]. Several participants applied their CFD condensation models in predicting the observed behavior, obtaining in general a good agreement with experimental results. 


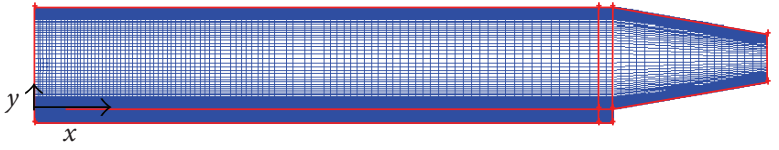

FIgure 12: Discretization adopted in the analysis of CONAN experiments by the FLUENT code with conjugated heat transfer.

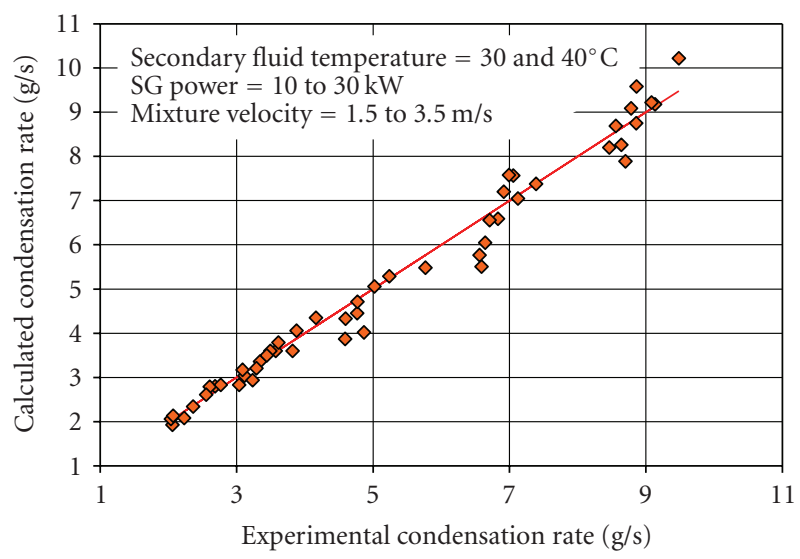

FIgURE 13: Comparison of a set of experimental data from the CONAN with FLUENT code predictions [35].

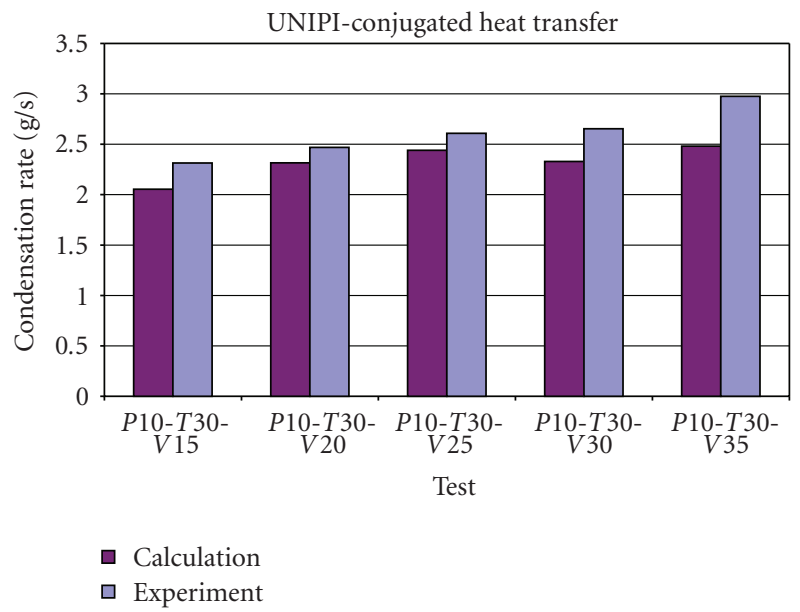

FIGURE 14: Results for the overall condensation rate obtained by the University of Pisa in the Condensation Benchmark Step-1.

Figures 14 and 15 illustrate the results obtained by the University of Pisa in the application of the FLUENT code to the 5 proposed tests. As it can be noted from Figure 14, the overall condensation rate is slightly underestimated, a feature that resulted common with other code results. This behavior can be explained considering Figure 15, that shows a corresponding underestimate of the local heat flux at the entrance of the test channel. Possible $3 \mathrm{D}$ effects as well as some degree of nonuniformity in the inlet mixture velocity can be considered as possible causes of this slight discrepancy.

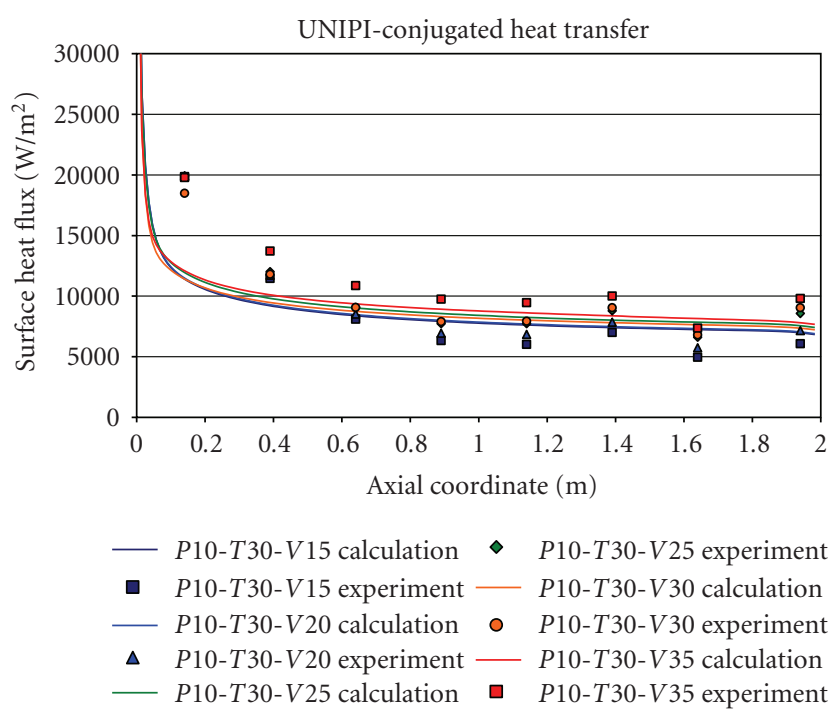

FIGURE 15: Results for the local heat flux obtained by the University of Pisa in the Condensation Benchmark Step-1.

\section{Conclusions}

The experience gained in simulating heat and mass transfer phenomena relevant for light water nuclear reactor applications provides a suitable basis to draw conclusions about the present capabilities of models in predicting evaporation and condensation in the presence of noncondensable gases.

As a first remark, it can be noted that, at both the level of engineering models and of CFD codes, evaporation and condensation can be dealt with by quite the same approaches, obtaining similar accuracy. On one side, the classical treatment of mass transfer on the basis of the definition of appropriate coefficients to be multiplied by a suitable driving force, making use of the analogy between heat and mass transfer, appears very effective. Once an applicable heat transfer correlation is selected for the addressed geometry, the analogy assures a reasonable degree of reliability of the corresponding mass transfer model. As a matter of fact, the step of selecting the heat transfer correlation is the one that differentiates the various applications discussed in this paper, ranging from rectangular channels with a falling film, to circular heat exchanger pipes and compact-finned tube heat exchangers. The diversity of the addressed geometries, in which the adopted approach proved to be effective, suggests a reasonable level of reliability.

In this respect, it must be also recognized that the role of the analogy between heat and mass transfer, though particularly evident in the case of the engineering correlation approach, is a key one also in CFD models. In fact, the adoption of constant values of the turbulent Prandtl and Schmidt numbers in defining the turbulent diffusivities on the basis of the eddy viscosity reveals the use of this assumption also in the case of mechanistic models having low Reynolds number capabilities. Therefore, even while using sophisticated two-equation turbulence models, we often still rely on the analogy between heat and mass transfer, something to be attentively considered when extrapolating 
our modelling experience to different fluids or operating conditions, for which this approach may be not completely justified or successful.

The effectiveness of computational fluid-dynamic techniques in providing plenty of detailed local data, to be compared with experimental information, is quite evident, though their suitability for practical applications can be matter of discussion. In this respect, we can identify two separate orders of problems.

(i) On one side, even for simple geometries, refining the meshes close to the walls, in order to fully exploit low-Reynolds number capabilities, may be too costly, requiring a huge number of finite volumes or elements and a corresponding increase of computational effort.

(ii) On the other side, complex geometries, like the finned-tubes heat exchangers, may anyway require great detail to be described making the use of CFD models, resulting particularly expensive for production calculations.

It seems therefore that CFD must be considered as a very powerful tool for obtaining relatively accurate results, though it is still not always completely affordable for studying system behavior in cases like complex experimental apparatuses or full-scale reactor plants. In this respect, the job of engineering models and correlations seems not yet to be completed, not only for quick guesses of heat and mass transfer rates, but also for inclusion in system analyses, requiring to model simultaneously many interacting phenomena.

As noted in the conclusions about the SARnet Benchmark [13], at least for simple geometries efforts can be spent in providing CFD codes with models suitable to reasonably predict mass transfer phenomena without introducing an unaffordable number of nodes in the near-wall region. This could be achieved by the use of specialized wall functions allowing for a realistic description of boundary layers. Though a proposal in this aim is already available, dealing by wall functions with intrinsically complicated phenomena as mixed convection may be challenging enough; some sort of compromise modelling should be then achieved, while waiting for increased computing power allowing for adopting more fundamental and mechanistic approaches.

\section{Nomenclature}

\section{Latin Letters}

$B: \quad$ Width $[\mathrm{m}]$

$B_{m}$ : Driving force for mass transfer in terms of mass fractions

$\mathrm{D}_{v g}$ : Vapor diffusion coefficient in the gas mixture $\left[\mathrm{m}^{2} / \mathrm{s}\right]$

$D_{h}$ : Hydraulic diameter $[\mathrm{m}]$

g: Gravity $\left[\mathrm{m}^{2} / \mathrm{s}\right]$

Gr: Grashof number

$h$ : Specific enthalpy $[\mathrm{J} / \mathrm{kg}]$

$h_{l v}$ : Latent heat of evaporation $[\mathrm{J} / \mathrm{kg}]$

$h_{m}$ : Mass transfer coefficient $\left[\mathrm{kg} /\left(\mathrm{m}^{2} \mathrm{~s}\right)\right]$ j: $\quad$ Node number

$L: \quad$ Length $[\mathrm{m}]$

$\dot{m}_{i}^{\prime \prime}$ : Interfacial mass flux $\left[\operatorname{kg}\left(\left(\mathrm{m}^{2} \mathrm{~s}\right)\right]\right.$

$\mathrm{Nu}$ : Nusselt number

$p_{0}$ : Reference pressure $[\mathrm{Pa}]$

Pr: Prandtl number

$q^{\prime \prime}$ : Heat flux $\left[\mathrm{W} / \mathrm{m}^{2}\right]$

Re: Reynolds number

$S_{h}$ : Energy volumetric source $\left[\mathrm{W} / \mathrm{m}^{3}\right]$

$S_{m}$ : Mass volumetric source $\left[\mathrm{kg} /\left(\mathrm{m}^{3} \mathrm{~s}\right)\right]$

Sc: Schmidt number

$T:$ Temperature $[\mathrm{K}]$

$U$ : X-component of fluid velocity $[\mathrm{m} / \mathrm{s}]$

$V:$ Y-component of fluid velocity $[\mathrm{m} / \mathrm{s}]$

$W$ : Mass flow rate $[\mathrm{kg} / \mathrm{s}]$

$x$ : Longitudinal coordinate $[\mathrm{m}]$

$y$ : Transversal coordinate $[\mathrm{m}]$

\section{Greek Letters}

$\Delta:$ Node thickness [m]

$\rho_{g}$ : Gas mixture density $\left[\mathrm{kg} / \mathrm{m}^{3}\right]$

$\omega$ : Mass fraction

\section{Subscripts}

b: Bulk

cond: Condensation

$f$ : Liquid

g: $\quad$ Gas mixture

$i$ : Interface

in: Inlet

min: Minimum

tu: Turbulent

$v$ : Vapor (steam)

$w: \quad$ Wall

0: At low mass transfer rate

$\infty$ : Asymptotic value

\section{References}

[1] M. D. Kennedy, F. E. Peters, M. D. Carelli, and A. T. Pieczynski, "Advanced PWR passive containment cooling system testing," in Proceedings of the International Topical Meeting on Advanced Reactor Safety, pp. 249-256, Pittsburgh, Pa, USA, April 1994.

[2] S. Tsunoyama, S. Yokobori, and K. Arai, "Development of passive containment cooling system," in Proceedings of the International Topical Meeting on Advanced Reactor Safety, Pittsburgh, Pa, USA, April 1994.

[3] M. Ishii, S. T. Revankar, R. Dowlati, et al., "Scientific Design of Purdue University Multi-Dimensional Integral Test Assembly (PUMA) for GE SBWR,” Purdue University Report PU-NE-94/1, U.S. Nuclear Regulatory Commission Report NUREG/CR-6309, 1996.

[4] G. Yadigaroglu, "Scaling of the SBWR Related Test," Report NEDO-32258, November 1993.

[5] G. Van Goethem, A. Zurita, J. M. Bermejo, P. Lemaître, and H. Bischoff, "Main achievements of FP-4 research in reactor safety," in Proceedings of FISA Meeting on EU Research in 
Reactor Safety (FISA '99), Luxembourg, Belgium, NovemberDecember 1999.

[6] K. Fischer, W. Ambrosini, N. Forgione, et al., "Scaling of containment experiments (SCACEX)," in Proceedings of FISA Meeting on EU Research in Reactor Safety (FISA '03), Luxembourg, Belgium, November 2003.

[7] F. Oriolo, A. Manfredini, A. Villotti, F. De Rosa, and S. Paci, "Evaluation of Containment Heat and Mass Transfer Models with Consideration of the Phebus-FP Containment Vessel," EUR 16111 EN, JRC Ispra Site, 1994.

[8] W. Ambrosini, N. Forgione, F. Oriolo, P. Vigni, and S. Valisi, "Prediction of condensation in a prototypical passive containment condenser," in Proceedings of the Post-SMiRT 14 International Seminar 18 on Passive Safety Features in Nuclear Installations, Pisa, Italy, August 1997.

[9] N. Forgione, W. Ambrosini, F. Oriolo, and P. Wackers, "Falling film evaporation in a rectangular channel with different depth," in Proceedings of the 10th International Conference on Nuclear Engineering (ICONE-10), vol. 4, pp. 699-704, Arlington, Va, USA, April 2002.

[10] W. Ambrosini, N. Forgione, F. Oriolo, and J. Wäsle, "Experimental investigation and modelling of film evaporation in the presence of countercurrent air flow," in Proceedings of the 18th UIT National Heat Transfer Conference, vol. 2, p. 617, Cernobbio, Italy, June 2000.

[11] L. Brusa, A. Bianchi, L. Mazzocchi, et al., "Modelling condensation on finned tube heat exchangers in the presence of noncondensable gases," in Proceedings of the 2nd International Symposium on Two-Phase Flow Modelling and Experimentation, Pisa, Italy, May 1999.

[12] W. Ambrosini, N. Forgione, F. Oriolo, C. Dannöhl, and H. J. Konle, "Experiments and CFD analyses on condensation heat transfer on a flat plate in a square cross section channel," in Proceedings of the 11th International Topical Meeting on Nuclear Reactor Thermal-Hydraulics (NURETH-11), Avignon, France, October 2005.

[13] W. Ambrosini, M. Bucci, N. Forgione, et al., "Comparison and analysis of the condensation benchmark results," in Proceedings of the 3rd European Review Meeting on Severe Accident Research (ERMSAR '08), Nesseber, Bulgaria, September 2008.

[14] W. Ambrosini, N. Forgione, A. Manfredini, and F. Oriolo, "On various forms of the heat and mass transfer analogy: discussion and application to condensation experiments," Nuclear Engineering and Design, vol. 236, no. 9, pp. 1013-1027, 2006.

[15] W. Ambrosini, N. Forgione, D. Mazzini, and F. Oriolo, "Computational study of evaporative film cooling in a vertical rectangular channel," Heat Transfer Engineering, vol. 23, no. 5, pp. 25-35, 2002.

[16] M. Bucci, M. Sharabi, W. Ambrosini, N. Forgione, F. Oriolo, and S. He, "Prediction of transpiration effects on heat and mass transfer by different turbulence models," Nuclear Engineering and Design, vol. 238, no. 4, pp. 958-974, 2008.

[17] A. S. Rao, C. D. Sawyer, and R. J. Candless, "Simplified boiling water reactor design," in Proceedings of the 1st JSME/ASME Joint International Conference on Nuclear Engineering (ICONE-1), Tokyo, Japan, November 1991.

[18] P. Masoni, S. Botti, and G. W. Fitzsimmons, "Confirmatory tests of full-scale condensers for the SBWR," in Proceedings of the 2nd JSME/ASME Joint International Conference on Nuclear Engineering (ICONE-2), pp. 735-744, San Francisco, Calif, USA, March 1993.

[19] P. Masoni, G. Bianchini, P. F. Billig, et al., "Tests on full scale prototypical passive containment condenser for SBWR's application," in Proceedings of the 3rd JSME/ASME Joint International Conference on Nuclear Engineering (ICONE-3), Kyoto, Japan, April 1995.

[20] W. M. Rohsenow, "A method for correlating heat transfer data for surface boiling of liquids," Transactions of the ASME, vol. 74, pp. 969-976, 1952.

[21] P. W. Dittus and L. M. K. Boelter, "Heat transfer in automobile radiators of the tubular type," University of California Publications in Engineering, vol. 2, no. 13, pp. 443-461, 1930.

[22] C. F. Bonilla, Heat Transfer, Interscience, New York, NY, USA.

[23] J. Stefan, "Versuche über die Verdampfung," Sitzungsberichte der Akademie der Wissenschaften, vol. 68, pp. 385-423, 1873.

[24] G. Ackerman, "Wärmeübertragung und molekulare Stoffübertragung im gleichen Feld bei grosser Temperatur und Partialdruckdifferenzen,” VDI ForschHft. 382, 1937.

[25] S. Banerjee and Y. A. Hassan, "Condensation heat transfer coefficient with noncondensable gases for heat transfer in thermal-hydraulic codes," in Proceedings of the $3 \mathrm{rd}$ JSME/ASME Joint International Conference on Nuclear Engineering (ICONE-3), Kyoto, Japan, April 1995.

[26] K. Almenas and U. C. Lee, "A statistical evaluation of the heat transfer data obtained in the HDR containment tests," University of Maryland, 1984.

[27] A. Manfredini, F. Mariotti, F. Oriolo, and P. Vigni, "A facility for the evaluation of heat flux from a plate cooled by a water film with counter-current air flow," in Proceedings of the 11th National Congress on Heat Transfer of the UIT, Milano, Italy, June 1993.

[28] Fluent Inc., "FLUENT 6.1 User’s Guide,” February 2003.

[29] V. Cavicchia and P. Vanini, "Innovative containment cooling for concrete containment of nuclear power plants," in Proceedings of the International Conference on Nuclear Containment, Cambridge, UK, September 1996.

[30] L. Mazzocchi, P. A. G. Vacchiani, and P. Vanini, "Finned tubes condensing heat transfer with mixtures of steam and non condensible gases," in Proceedings of the European Two-Phase Flow Group Meeting, Grenoble, France, June 1996.

[31] F. de Cachard, S. Lomperski, and G.-R. Monauni, "The first LINX-2 tests," in Proceedings 5th International Conference on Nuclear Engineering (ICONE-5), Nice, France, May 1997, paper 2448.

[32] K. O. Beatty Jr. and D. L. Katz, "Condensation of vapors on outside of finned tubes," Cemical Engineering Progress, vol. 44, no. 1 , pp. 55-70, 1948.

[33] T. M. Rudy and R. L. Webb, "An analytical model to predict condensate retention on horizontal integral-fin tubes," Journal of Heat Transfer, vol. 107, pp. 361-368, 1985.

[34] A. Nir, "Heat transfer and friction factor correlations for crossflow over staggered finned tube banks," Heat Transfer Engineering, vol. 12, no. 1, pp. 43-58, 1991.

[35] W. Ambrosini, N. Forgione, S. Mogliani, and F. Oriolo, "Discussion of heat and mass transfer models on the basis of experiments and CFD calculations," in Proceedings of the United Kingdom National Heat Transfer Conference (UKHTC '05), Manchester, UK, September 2005. 

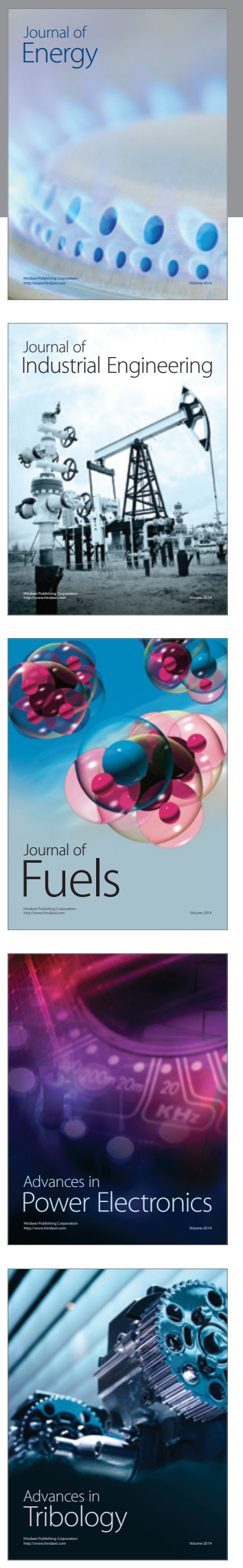
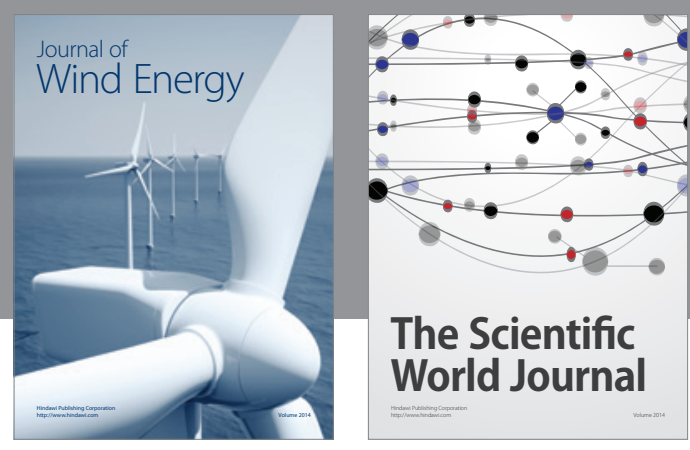

The Scientific World Journal

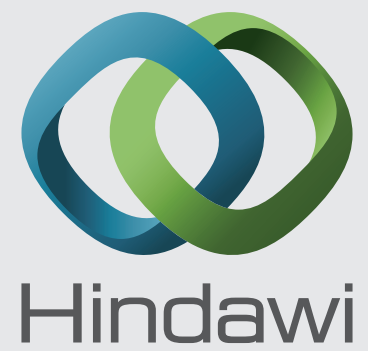

Submit your manuscripts at http://www.hindawi.com
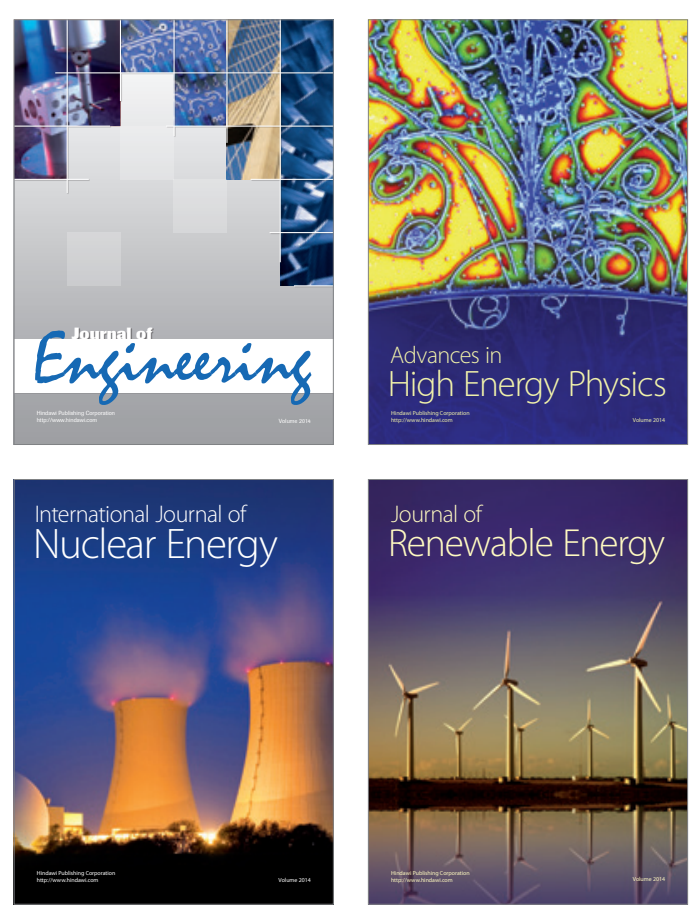

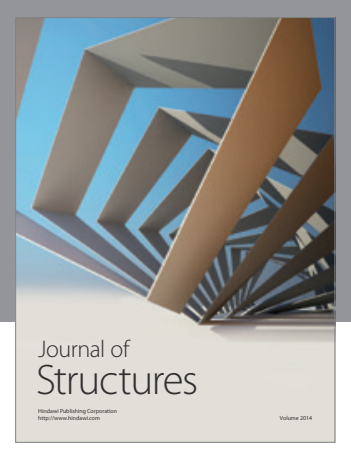

Rotating
Mechinery
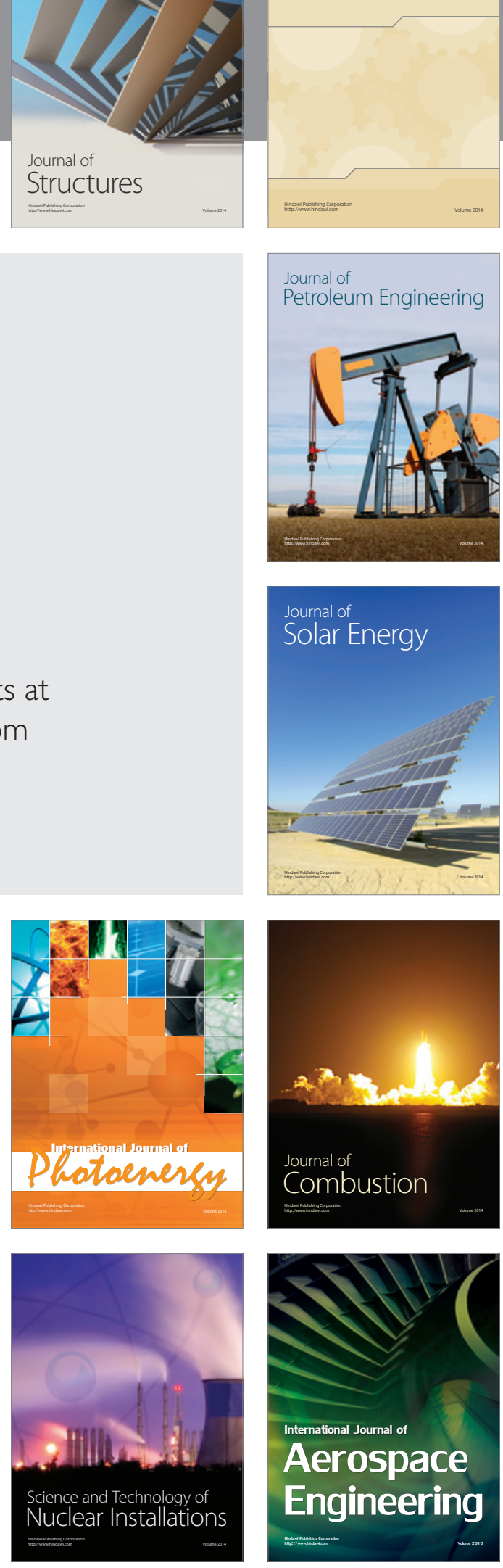